\title{
AS TRÊS DIMENSÕES DO DIREITO NA FILOSOFIA CRÍTICA DE KANT
}

\section{Leonam Baesso da Silva Liziero ${ }^{1}$}

\section{Resumo}

O presente artigo visa apresentar as três dimensões do direito dentro da filosofia crítica de Immanuel Kant e suas especificações. Inicialmente será vista como a liberdade é manifestada pelo agir racional prático, em oposição ao conhecimento da tradicional metafísica até então. A autonomia humana permite que a liberdade seja possível, tanto no mundo moral, quanto no Estado. Posteriormente o trabalho demonstrará a divisão do direito na obra de Kant, em direito público e direito natural. Enquanto o primeiro é claramente identificado com a legislação emitida por autoridades, em seus três níveis (o direito do Estado, o direito das gentes e o direito cosmopolita), o segundo tem dois sentidos diferentes: o direito natural derivado enquanto direito privado, sem a existência do Estado e o direito natural inato (Naturrecht), a realização da liberdade, sendo o fundamento último, tanto do direito privado quanto do público, em quaisquer que sejam seus níveis.

Palavras-Chave: Immanuel Kant; Naturrecht; Liberdade.

\section{INTRODUÇÃO}

É inegável a contribuição de Immanuel Kant (1724-1804) para a formação do pensamento jurídico moderno. A filosofia kantiana aborda o problema do direito de forma mais específica na Metafísica dos Costumes, mas assim como todo tema em sua obra, sua visão a respeito da ontologia do direito e sua finalidade pressupõe o entendimento do sentido de moral e liberdade, que o autor desenvolve como solução à questão sem resposta imediata ao final de sua Crítica da Razão Pura.

O presente artigo discutirá os sentidos do direito em sua obra, procurando responder a um questionamento interpretativo: é possível dizer que há mais de dois sentidos? O posicionamento que será apresentado é a leitura a respeito das três dimensões da ontologia jurídica em suaobra.

Incialmente será tratado de forma breve um dos problemas epistemológicos que Kant busca desvendar em seu epopeico caminho na Crítica da Razão Pura: a possiblidade de se conhecer juízos sintéticos apriorísticos de conceitos abstratos em si, como Deus, imortalidade e liberdade. Este último será um dos núcleos do kantismo,

\footnotetext{
${ }^{1}$ Doutorando em Teoria e Filosofia do Direito pela Universidade do Estado do Rio de Janeiro - UERJ. E-mail: leonamliziero@gmail.com
} 
sendo amplamente debatido nas Crítica da Razão Prática e na Fundamentação da Metafísica dos Costumes, ambas obras essenciais para a compreensão da dimensão de direito natural queaqui explanada.

A ideia de liberdade se vincula ao agir moral, que será investigada em uma parte posterior deste escrito. $\mathrm{O}$ homem que se comporta de acordo com o imperativo de moralidade, age com liberdade. Nesta parte será tratada brevemente o sentido de liberdade desenvolvido por Kant e sua importância para a concepção de direito e para a justificativa de legitimidade do Estado, cuja finalidade imediata é a preservação da coexistência da liberdade entre os homens.

Posteriormente serão debatidas as dimensões do direito no pensamento kantiano, começando pelo direito do Estado. Neste ponto serão apresentadas algumas de suas características e debatida a possiblidade de autonomia desta dimensão das outras. Vale um breve contraponto com o pensamento hobbesiano sobre a independência o uso do jusnaturalismo como discurso legitimador para a lei legislada e imposta pelo Estado.

O problema das outras dimensões será tratada no tópico seguinte. Será realizada discussão se há apenas um sentido de direito natural ou dois deles, conforme o que é defendido neste trabalho. Por fim, apresentar-se-á a reelaboração que Immanuel Kant faz a respeito do direito natural e como ele se diferencia de algumas elaborações anteriores.

\section{CRÍTICISMO METAFÍSICO E A RAZÃO PRÁTICA}

O primeiro aspecto da obra de Kant a ser debatida é sua Crítica da Razão Pura, obra cujo principal objeto é a epistemologia. Kant questiona como é possível o conhecimento científico dos conceitos. Para isso, ele inicia um árduo caminho a respeito do objeto do conhecimento e do processo do conhecer, que envolvem as questões sensitivas e categóricas.

Em primeiro lugar, Kant procura desvendar que tipos de juízos são efetivamente objetos do conhecimento científico. Prontamente o autor não reconhece a possiblidade de conhecer cientificamente dois tipos: os juízos analíticos de conhecimento a priori e os juízos sintéticos a posteriori, sendo portanto o objeto de investigação de sua obra os juízos sintéticos a priori. Estas noções merecem uma sucinta explicação.

O autor distingue, no começo de sua obra, dois tipos de conhecimento: o puro e o empírico. Embora, nenhum conhecimento precede o homem, ou seja, começa com a experiência, é possível afirmar que nem todo conhecimento é oriundo da experiência; nem todo conhecimento é resultado de uma combinação das sensações. O conhecimento puro é denominado como a priori, enquanto o empírico, a posteriori. O conhecimento a priori não é independente de uma experiência em si, mas sim de toda a experiência. Portanto, este tipo de conhecimento é composto por duas características: necessidade e universalidade. Um conhecimento apriorístico sempre será 
rigorosamente necessário e universal ao formar um juízo, diferentemente do conhecimento empírico, cuja universalidade é feita basicamente por indução.

Kant vê que é preciso investigar tais conceitos que transcendem os limites da experiência. Estes conceitos por não serem passíveis de experimentação, não podem ser captados ou conhecidos por meio de sensações, mas somente por meio da razão pura. Uma das ciências que se preocupam com este conhecimento é a Metafísica, que trata de conhecer conceitos como Deus, imortalidade e liberdade - explorados por Kant no final da Crítica da Razão Pura.

Os juízos, sentenças nas quais é possível uma afirmativa ou negativa, são analíticos ou sintéticos. Serão analíticos quando seu predicado desmembrar algo que já está contido no sujeito e sintéticos quando "acrescentam ao conceito do sujeito um predicado que de modo alguma era pensado nele nem poderia ter sido extraído dele por desmembramento"2. Os primeiros, Kant nomina por juízos de elucidação e os segundos por juízos de ampliação.

Por exemplo, dizer que todo metal tem extensão é um juízo analítico. Ser extenso já é próprio à ideia de objeto, então quando há predicados que realizam este tipo de situação eles apenas elucidam o sujeito, não transformando ou acrescentando nada de novo. Ao contrário, um juízo sintético seria dizer que todo metal é diluído quando exposto a alguma alta temperatura. O predicado neste caso acrescenta algo novo ao sujeito.

Os dois tipos de conhecimento podem se intercalar com os dois tipos de juízos: todo conhecimento empírico é sintético. Sempre que se obtém um conhecimento derivado da experiência, ele será a síntese de um sujeito que sofre alguma influência do predicado. Na clássica proposição lógica, "todo homem tem coração" é possível perceber a indução da experiência (tem coração) aos sujeitos (todo homem). Todo juízo científico praticamente será sintético a posteriori, salvo nas ciências teóricas darazão.

O conhecimento apriorístico sintético está presente nas ciências da razão, para o autor, a Matemática, a Física e a Metafísica. Serão sobre essas três ciências que o problema geral da razão pura será colocado: como são possíveis juízos sintéticos a priori? E principalmente: como é possível a Metafísica como ciência? Kant realiza uma crítica ao que já foi abordado sobre a Metafísica como um conhecimento dogmático; o que já foi discorrido sobre ela basicamente se resume a desdobramento de juízos analíticos.

A Crítica da Razão Pura é uma ciência especial "que contém os princípios para conhecer algo absolutamente a priori. Um órganon da razão pura seria um conjunto daqueles princípios segundo dos quais todos os conhecimentos puros a priori podem ser adquiridos e efetivamente realizados" ${ }^{3}$ Kant tratará de diversos assuntos em seu caminho epistemológico até chegar na última parte, no qual discute a crítica às tradicionais concepções da metafísica.

${ }^{2}$ KANT, Immanuel. Crítica da Razão Pura. 2 ed.Trad. Valério Rohden. São Paulo: Abril Cultural, 1983, p.27.

${ }^{3}$ KANT, Immanuel. Crítica da Razão Pura. 2 ed.Trad. Valério Rohden. São Paulo: Abril Cultural, 1983, pp. $32-33$ vol.09, nº. 02, Rio de Janeiro, 2016.pp. 1175-1193 
No seu debate sobre se é possível conhecer os conceitos da Metafísica - que devem ser independentes de experiência - Kant acaba por concluir que a pretensão é contraditória em si: não é possível conhecer os conceitos da metafísica, ou seja, das coisas em si, sem ultrapassar as limitações do ato de conhecer, que o autor analisa na Estética e na Analíticatranscendental.

Então, não sendo possível saber os conceitos em si como um conhecimento puramente teórico, é possível que seja determinado de outra forma? Kant afirma que os conceitos podem ser conhecidos também sem sua dimensão prática, ou seja, não são cognoscíveis em um ato especulativo e sim em uma ação. Neste sentido apenas é que podem ser encontrados os conceitos da Metafísica.

\section{MORALIDADE E LIBERDADE}

Os conceitos de moralidade e liberdade na filosofia kantiana estão necessariamente vinculados. O ser humano é livre por agir de acordo com a moral revelada pelo imperativo categórico.

Kant estabelece certa sistematização do direito, dividido em direito natural e direito positivo. Enquanto o primeiro encontra suas bases em princípios a priori, o segundo corresponde a uma ação externa volitiva do legislador, a autoridade de um Estado para a criação do direto.

A liberdade, fundamento da razão prática, é o direito inato e o valor que condiciona o ideal por trás das normas do direito público; "é o único direito original pertencente a todos os homens em virtude da humanidade deles"4. Percebe-se uma justificativa jusnaturalista, mas com uma noção de direito natural de índole racionalista diferente de antecessores como Grotius eLocke.

O inatismo do direito é fruto do exercício racional da ação moral dada pelo imperativo categórico. Somente é possível conhecer a liberdade pela ação - o que Kant desenvolve após uma metafísica não possível de ser conhecida pela especulação pura, apenas pela prática pura. Segundo o autor, "a razão é que conhecemos nossa liberdade (todas as leis morais e assim todos os direitos, bem como os deveres) somente através do imperativo moral, que é uma proposição que ordena o dever". ${ }^{5} \mathrm{O}$ dever é uma relação entre uma lei objetiva racional e uma vontade subjetiva, sendo os imperativos as fórmulas de um mandamento, ou seja, "são apenas fórmulas para exprimir a relação entre leis objetivas do querer em geral e a imperfeição subjetiva deste ou daquele ser racional, da vontade humana."

Para se compreender a relação entre moral e liberdade, culminada na noção de imperativo categórico, é necessário verificar a evolução do conceito que o autor desenvolve em sua Fundamentação da Metafísica dos

\footnotetext{
${ }^{4}$ KANT, Immanuel. A Metafisica dos Costumes. Trad. Edson Bini. Bauru: Edipro, 2008, p. 83.

${ }^{5}$ KANT, Immanuel. A Metafisica dos Costumes. Trad. Edson Bini. Bauru: Edipro, 2008, p. 85

${ }^{6}$ KANT, Immanuel. Fundamentação da Metafísica dos Costumes. Trad. Tania Maria Bernkopf. São Paulo: Abril Cultural, 1984, p. 124.
} 
Costumes: "Age apenas segundo uma máxima tal que possas ao mesmo tempo querer que ela se torna lei universal." ${ }^{\text {O }} \mathrm{O}$ imperativo categórico é uma fórmula racional que determina que a vontade humana deve agir apenas pelo dever e não agir com uma intenção de se alcançar alguma finalidade. A ação tendo em vista um objetivo, em uma relação de causa e consequência, é o que Kant denomina por imperativo hipotético. Ao diferenciar as duas formas de imperativos, disserta oautor:

Todos os imperativos são fórmulas de determinação da ação que é necessária segundo o principio de uma vontade boa de qualquer maneira. No caso de a ação der apenas boa como meio para qualquer outra coisa, o imperativo é hipotético; se a ação é representada como boa em si, por conseguinte, como necessária numa vontade em si conforme à razão como principio dessa vontade, então o imperativo écategórico. ${ }^{8}$

A máxima moral é dada pelo imperativo categórico, a ação segundo um dever cuja motivação é o cumprimento do próprio dever em si. O homem não deve agir com alguma finalidade em vista, mas sim por meramente cumprir seu dever, tornando sua vontade boa e condizente com o comando racional. Explica Palombella: "Kant define como moral uma ação que derive da boa vontade, e é boa a vontade que parta apenas do impulso de obediência ao dever moral, do imperativo categórico, o imperativo moral como únicofim".

$\mathrm{Na}$ definição de Kant, o imperativo categórico "é aquele que representa uma ação como objetivamente necessária e a torna necessária não indiretamente através da representação de algum fim a ser atingido pela ação, mas através da mera representação dessa própria ação." ${ }^{10} \mathrm{O}$ conteúdo desse imperativo é uma ordem da razão simples e com um caráter de pressuposição: cada um deve agir de forma que sua ação se torne uma lei universal, ou seja, deve-se agir como se de forma pressuposta todas as pessoas agissem da mesma forma; há um sentido de comando destinado a uma universalidade de sujeitos.

Esse imperativo categórico está relacionado à ideia de moralidade; sua ação moral é a conduta de acordo com este comando formal do imperativo. Isto é pressuposto de todo homem devido á sua racionalidade; pode ser aplicado a todo homem, já que é um comando puro racional oriundo de manifestação de vontade. Segundo Kant, "a vontade é concebida como a faculdade de se determinar a si mesmo a agir em conformidade com a representação de certas leis. E uma faculdade só se pode encontrar em seresracionais." ${ }^{11}$

Nesse aspecto, a agir racional é um agir racional é moral por ser o cumprimento do dever pelo dever. E esta ação moral é uma ação livre. O homem age com liberdade quando age de acordo com seu dever revelado pelo imperativo categórico, pois age racionalmente. Observa-se um abandono de uma noção de liberdade

\footnotetext{
${ }^{7}$ KANT, Immanuel. Fundamentação da Metafísica dos Costumes. Trad. Tania Maria Bernkopf. São Paulo: Abril Cultural, 1984, p. 129

${ }^{8}$ KANT, Immanuel. Fundamentação da Metafísica dos Costumes. Trad. Tania Maria Bernkopf. São Paulo: Abril Cultural, 1984, p. 125

${ }^{9}$ PALOMBELLA, Gianluigi. Filosofia do Direito Trad. Ivone Benedetti. São Paulo: Martins Fontes, 2005, p. 63.

${ }^{10}$ KANT, Immanuel. A Metafísica dos Costumes. Trad. Edson Bini. Bauru: Edipro, 2008, p. 65

${ }^{11}$ KANT, Immanuel. Fundamentação da Metafisica dos Costumes. Trad. Tania Maria Bernkopf. São Paulo: Abril Cultural, 1984, p. 134
} 
moderna até então desenvolvida e a inovação no conceito de liberdade revelado no agir de acordo com a moral, não mais no mero exercício especulativo.

Explica Michael Sandel: "O valor moral de uma ação não consiste suas consequências, mas na intenção com a qual é realizada. O que importa é o motivo, que deve ser de uma determinada natureza. O que importa é fazer a coisa certa porque é a coisa certa." ${ }^{12}$

A universalidade do imperativo encontra-se na extensão de racionalidade a todo ser humano, independentemente de características individualizantes ou condições sociais. Todo ser humano é dotado de racionalidade e por isso é capaz de agir racionalmente porque é capaz de se comportar de acordo com imperativos. Evidentemente isso não significa que todo homem se comportará todo tempo conforme os postulados da razão, já que as emoções podem leva-lo a um comportamento desviado todavia a possiblidade do comportamento racional existe e é extensível a todos. É uma pressuposição formal; toda pessoa é racional.

Por ser capaz de conhecer as máximas racionais, o homem escolhe ou não se comportar de acordo com sua própria lei racional, que de acordo com o imperativo categórico, determina que ele se comporte como todos os homens se comportariam agindo pelas suas próprias leis racionais. O homem desta forma possui autonomia, um termo chave para a compreensão da relação entre moralidade eliberdade.

Autonomia da vontade é aquela sua propriedade graças à qual ela é para si mesma sua lei (independentemente da natureza dos objetos do querer). O princípio da autonomia é portanto: não escolher senão de modo a que as máximas da escolha estejam incluídas simultaneamente, no querer mesmo, como leu universal. ${ }^{13}$

A possiblidade de agir racionalmente e logo dotado de autonomia, cria um vínculo necessário entre toda a humanidade, uma vez que a racionalidade os torna sujeitos da mesma lei universal e torna a ideia de vida humana fundamental. Uma vez como ser racional, o homem não pode ser instrumentalizado; a ação racional tende a considerar a vida como um fim em si mesma devido à sua natureza. Explica Kant: "a natureza racional existe como um fim em si. É assim que o homem se representa necessariamente a sua própria existência; e neste sentido, este principio é um principio subjetivo das ações humanas. ${ }^{14}$ Oposto a este conceito de autonomia, Kant propõe o de heteronomia, que determina o dever do agir por fatores externos ao próprio sujeito, quaisquer que sejam eles.

Veja-se: quando o homem age de acordo com leis que não são as leis morais, reveladas pela razão, há uma situação de heteronomia. $\mathrm{O}$ direito, como "a soma das condições sob as quais a escolha de alguém pode ser unida á escolha de outrem de acordo com uma lei universal de liberdade", é uma legislação externa ao sujeito, cuja

\footnotetext{
${ }^{12}$ SANDEL. Michael. Justiça: O que é fazer a coisa certa. Trad. Heloisa Matias. Rio de Janeiro: Civilização Brasileira, 2012, p.151.

${ }^{13}$ KANT, Immanuel. Fundamentação da Metafísica dos Costumes. Trad. Tania Maria Bernkopf. São Paulo: Abril Cultural, 1984, p. 144.

${ }^{14}$ KANT, Immanuel. Fundamentação da Metafísica dos Costumes. Trad. Tania Maria Bernkopf. São Paulo: Abril Cultural, 1984, p. 135.
} 
origem racional é o contrato social, ainda que em uma perspectiva diferente de filósofos anteriores como Hobbes e Rousseau. ${ }^{15}$

Essa noção se coaduna com a outra divisão do direito que Kant faz entre direito inato - a liberdade propriamente dita - e o direito adquirido.

\section{DIMENSÕES DO DIREITO E O DIREITO PÚBLICO}

A divisão do direito em Kant, conforme o ponto de vista abordado neste trabalho obedece a três dimensões, que podem ser colocadas ao lado da ressignificação do direito natural feita pelo autor.

As três dimensões do direito, correspondentes a três níveis, podem ser descritas como: a) natürliche Recht, o direito do homem no estado de natureza como um pressuposto epistemológico; b) Naturrecht, o direito natural, em um aspecto transcendental do dever moral como liberdade; c) öffentliche Recht, o direito público, que é o direito emitido pelo Estado. Neste tópico será tratado deste ultimo.

Billier e Maryioli sistematizam essas três dimensões ou níveis do direito:

Das natürliche Recht, o direito do homem natural, o direito eventual ou hipotético do homem ao estado natural, ou seja, o que seria o direito privado independentemente de sua inscrição e um sistema de direto público [...] O Naturrecht, o direito natural propriamente dito, nível metapositivo do direito que transcende o direito estabelecido [...] $\mathrm{O}$ direito público, direito civil ou político, das öffentliche Recht, que designa o direito existente no Estado, o direito positivo. ${ }^{16}$

Percebe-se que há, entre estes níveis do direito feita por Kant, uma sequência entre os níveis que são interligados: há um direito inato transcendental proveniente da vontade do homem se comportar conforme uma lei universal e portanto ser livre; há direitos preexistentes e provisórios, de natureza privatista do homem em razão de sua humanidade, que necessita ser regulamentado e protegido pelo direito legislado do Estado, caracterizado por ser uma legislação heterônoma, diferente da lei racional cuja diretriz é o dever de comportamento segundo o imperativo categórico.

A sequência aqui trabalhada debate essa tridimensionalidade do direito em Kant. A existência do direito público é notável; resta o debate sobre a diferenciação das "duas formas direitos naturais" e sua relação com o contratualismo kantiano. Desta forma, está sendo feita uma regressão: inicia-se aqui explicação sobre alguns aspectos principais do direito público para depois se verificar o fundamento nestas duas dimensões do direito natural.

\footnotetext{
15 "Contra o racionalismo dogmático e contra o jusnaturalismo modernos, Kant mostrou que, na fundação pura do contrato social, exprime-se o homo noumenon: é por isso que a "simples ideia de razão", que o pacto de união civil é, indica o Ideal que, tal como uma esperança, ilumina os caminhos de uma humanidade em marcha” (GOYARD-FABRE, Simone. Filosofia Crítica e Razão Jurídica.São Paulo: Martins Fontes, 2006,pp. 179-180)

${ }^{16}$ BILLIER, Jean-Cassien; MARYIOLI, Aglaé. História da Filosofia do Direito. Trad. Maurício de Andrade. Barueri: Manole, 2005, pp. 163-164
} 
O direito público é principalmente descrito por Kant em sua Doutrina do Direito. Inicialmente o autor o considera como o direito do Estado em si, o primeiro dos três estágios do direito positivo - que será brevemente explicado mais tarde. O direito público é, conforme a filosofiakantiana,

Um sistema de leis para um povo, isto é uma multidão de seres humanos, ou para uma multidão de povos que, porque se afetam entre si, precisam de uma condição jurídica sob uma vontade que os uma, uma constituição (constitutio), de sorte que possam fruir o que é formulado como direito. ${ }^{17}$

É necessário desmembrar este complexo conceito kantiano. O direito público prescinde de um anterior contrato como produto da vontade dos homens de saírem do estado de natureza. Então, é necessário um sistema de leis que regulamente a vida social, com a finalidade para qual ele foi criado: a proteção da liberdade individual como comportamento moral. E evidentemente o sistema de leis é criado para seus destinatários, o povo ou uma multidão de povos.

Kant já considera o povo como uma parte essencial da formação do Estado, provavelmente por influencias de autores como Rousseau. De fato, uma de suas definições de Estado é "o conjunto de indivíduos numa condição jurídicas em relação aos seus próprios membros". ${ }^{18} \mathrm{O}$ direito pode ser destinado a um povo específico, ou seja, apenas um povo de um Estado ou a uma multidão de povos. Este nível do direito público vai além do Estado e é definido por Kant como ius gentium, o direito das gentes, que abarca as relações jurídicas entre os diferentes Estados.

Interessante é notar também a importância da vontade na definição do direito público. Muito além da expressão da vontade do soberano, como na teoria hobbesiana, a vontade dos cidadãos é o determinante para a formação do direito do Estado. Todas as vontades particulares dos homens, com a ação destinada à liberdade, são unidas em uma única vontade, que representa portanto a maneira pela pela qual a multiplicidades de indivíduos podem se manter como apenas um. Essa vontade toma uma forma, a constituição, imprescindível para que os indivíduos possam fruir das leis, sob a forma do direito.

O sentido republicano - mais uma vez demonstrando a forte influência de Rousseau - está presente neste conceito, ao se pensar a vontade geral como um produto racional que coordena as vontades particulares, de forma que todos os homens, nesse caso, necessitam se submeter ao direito que é produto - ainda que indiretamente - da vontade de cada um, resultante de um agir racional. A liberdade individual no estado de natureza de cada qual é reassumida em uma liberdade como membro de um povo. Não significa diretamente o aprisionamento da liberdade da mesma forma que na filosofia rousseauniana, mas sim ou outro significado para a liberdade além daquela inicial, como autonomia.

\footnotetext{
${ }^{17}$ KANT, Immanuel. A Metafisica dos Costumes. Trad. Edson Bini. Bauru: Edipro, 2008, p. 153

${ }^{18}$ Idem.
} vol.09, no. 02, Rio de Janeiro, 2016.pp. 1175-1193 
Sobre este aspecto, "o exercício da liberdade como autonomia é o que permite ao individuo superar, pelo menos em abstrato, o sentido de estraneirade e de heteronomia da esfera pública." ${ }^{19}$

O contratualismo kantiano é determinado pela necessidade da união de vontades em apenas uma, constituindo-se o corpo político. Kant, ao debater sobre a dignidade do Estado, como um ente superior à todos (o povo unido) define que o contrato social é o ato formador do Estado. Neste sentido, "a se expressar rigorosamente, o contrato original é somente a ideia desse ato, com referência ao qual exclusivamente podemos pensar na legitimidade do Estado". ${ }^{20} \mathrm{O}$ contrato de Kant se difere dos demais anteriores por não ser uma mera ficção hipotética para a constituição e instauração do Estado perante a sociedade civil.

O contrato kantiano não é um fato hipotético, mas sim uma ideia presente na qual um povo constitui um Estado pela convergência de suas vontades, formando uma vontade pública e geral ${ }^{21}$. O Estado para Kant não é uma coisa ou uma ente natural, mas uma pessoa moral, já que é o vórtice das vontades dos indivíduos que compõem determinada sociedade. Explica Simone Goyard-Fabre que "a razão crítica, transpondo o patamar que lhe permite interrogar-se sobre o direito público, percebeu, a necessidade de recorrer, para legitimar toda ordem jurídica real ou possível, ao contrato social enquanto fundamento normativo irrecusável do Estado."22

O contrato social de Kant é a identificação de uma máxima moral de forma a tornar possível a coexistência de vontades emanadas pela razão humana e que deve ser seguida por essa mesma vontade, uma vez que o indivíduo deve agir pensando no agir de todos os outros. ${ }^{23} \mathrm{~A}$ ideia de moralidade, expressada pela razão na forma do imperativo, está associada à de liberdade. Ao agir conforme o imperativo categórico, o indivíduo é autônomo. A autonomia "envolve dois componentes. O primeiro é que nenhuma autoridade externa é necessária para constituir ou nos informar das regras de moralidade. [...] O segundo é que no autogoverno podemos efetivamente nos controlar. ${ }^{\text {24 }}$ Sendo autônomo, é livre para seguir a finalidade de sua existência - a felicidade em conformidade com o imperativo criado por sua razão em um exercício de vontade.

\footnotetext{
${ }^{19}$ PALOMBELLA, Gianluigi. Filosofia do Direito Trad. Ivone Benedetti. São Paulo: Martins Fontes, 2005, p. 83

${ }^{20}$ KANT, Immanuel. A Metafisica dos Costumes. Trad. Edson Bini. Bauru: Edipro, 2008,p. 158.

${ }^{21}$ "Kant desenvolve então uma teoria contratualista, que se distingue das de seus antecessores por não pressupor que a liberdade seja limitada, mas sim deixada totalmente em favor da aquisição da liberdade como autonomia: o homem abandona a "liberdade selvagem e sem lei" para "reencontrar em um estado jurídico sua liberdade em geral." In: NOUR, Soraya. À Paz Perpétua de Kant: Filosofiado DireitoInternacionale das Relaçóes Internacionais.SãoPaulo: Martins Fontes, 2004,p.41.

${ }^{22}$ GOYARD-FABRE, Simone. Filosofia Crítica e RazãoJurídica.São Paulo: Martins Fontes, 2006, p.165

${ }^{23}$ "Da pressuposição desta ideia decorreu porém também a consciência de uma lei de ação que diz que os princípios subjetivos das ações, isto é, as máximas, tem que ser sempre tomados de modo a valerem também objetivamente, quer dizer, a valerem universalmente como princípios e portanto a poderem servir para nossa própria legislação universal" (KANT, Immanuel. Fundamentação daMetafisicados Costumes.SãoPaulo: Abril Cultural, 1983,p.151.)

24"Autonomy involves two components. The first is that no authority external to ourselves is needed to constitute or inform us of the demands of morality. We can each know without being told what we ought to do because moral requirements are requirements we impose on ourselves. The second is that in self-government we can effectively control ourselves. The obligations we impose upon ourselves override all other calls for action, and frequently run counter to our desires. In: SCHNEEWIND, J.B. Autonomy, obligation, and virtue: A overwiew of Kant,s moral philosophy. In: GUYER, Paul (org.) The Cambridge Companion of Kant. Cambridge: Cambridge University Press, 1992, p.309
} 
O Estado para Kant, seguindo uma tradição da abordagem contratualista, é "a união de uma multidão de seres humanos submetidas a leis de direito". ${ }^{25} \mathrm{O}$ Estado é formado pela associação entre homens que são sujeitos ao que o autor chama por leis de direito. Não basta apenas serem leis, mas sim serem de acordo com os princípios jurídicos, cujos fundamentos se encontram em outra dimensão do direito, no direito natural inato da liberdade.

O Estado é formado por única vontade geral que ao mesmo tempo se manifesta em três poderes (Gewalten): a soberania, exercida pelos legisladores; o poder executivo que é exercido pelo governante dentro dos limites da lei; e por fim, o poder judiciário, cuja função é dizer o que é de direito a cada qual, também limitado pelo texto legal.

A relação entre poder legislativo, executivo e judiciário - nesta ordem - correspondem ao silogismo prático, que na denominação kantiana são estabelecidos como: a) Oberstaz, a premissa maior, que é a lei da vontade geral; b) Untersatze, a premissa menor que contém uma ordem para que o destinatário se comporte de acordo com a lei, a premissa maior, uma vez que a ela está subordinado; c) Schlussstaze, a conclusão, que se reveste na sentença, norma que contém um comando para a aplicação do direito em um caso concreto.

Os três poderes do Estado se estabelecem em uma constituição, em uma relação de superioridade sobre os sujeitos que por sua vez compõem o Estado em uma unicidade. É uma relação mútua: Os indivíduos são sujeitos de direito em relação ao Estado e são sujeitos ao Estado, que não é ninguém senão a totalidade dos cidadãos. A relação entre os três poderes do Estado é ao mesmo tempo de coordenação e subordinação.

Nesse sentido, escreve Guyer:

Kant enfatiza que o governante ou o poder executivo de um Estado existe para fazer cumprir as leis aprovadas pelo Legislativo e não para servir os seus próprios interesses, insistindo que, em uma Constituição genuinamente republicana o governante não pode ser considerado como o proprietário da terra, garantindo a posse de sua própria terra para outros assuntos apenas como the aprouver. ${ }^{26}$

Os poderes são coordenados porque cada qual funciona como uma pessoa moral que se complementa com outra para a formação da constituição; e são subordinados a eles próprios, em um sistema de observância múltipla, de maneira que a função de um não seja usurpada por outro. ${ }^{27}$

O próximo estágio do direito público, além do direito do Estado é o direito das gentes. Este nível cuida das normas jurídicas entre os diversos Estados. Analogicamente o Estado vive em um estado de natureza, da mesma forma que os homens sem o Estado. Uma vez que o Estado é uma pessoa sem uma autoridade superior, ele tende a entrar em conflito com um semelhante. Na condição de pessoa moral, formada pela razão, o Estado é

\footnotetext{
${ }^{25}$ KANT, Immanuel. A Metafisica dos Costumes. Trad. Edson Bini. Bauru: Edipro, 2008, p. 155.

${ }^{26}$ GUYER, Paul. Kant. London: Routledge, 2006, p.293. Do original em inglês: "Kant emphasizes that the ruler or executive power of a state exists to enforce the laws passed by the legislature and not to serve its own interest by insisting that in a genuinely republican constitution the ruler cannot be regarded as the proprietor of the land, granting tenure of his own land to other subjects only as he sees fit".

${ }^{1184}$ KANT, Immanuel. A Metafisica dos Costumes. Trad. Edson Bini. Bauru: Edipro, 2008, p. 158.
} 
"considerado como vivendo em relação com um outro Estado na condição de liberdade natural e, portanto, numa condição de guerra constante". ${ }^{28}$

Neste ponto há uma semelhança com o estado de natureza hobbesiano. De fato, é possível considerar as relações entre Estados como um cenário que configura uma situação de tensão constante entre eles, da mesma forma que o homem hobbesiano eu seu estado de natureza. Kant neste aspecto considera que os Estados em tal cenário no qual eles exercem seus direitos relativos à guerra, apesar de ser uma condição não jurídica, uma vez que há a ausência de uma autoridade superior que os coloque em uma posição desubordinação.

Para evitar este estado de guerra, a única solução seria um contrato racional entre os Estados com tal finalidade. Veja-se que Kant não defende um super Estado que subordine os demais e sim o compromisso pela via do direito que seja obrigatório a todos que o assumirem. Tal contrato forma liga dos Estados que tem como finalidade protegê-los mutualmente dos ataques externos.

$\mathrm{Na}$ formação da liga cria a condição jurídica entre os Estados, o jus gentium, direito comum a uma família destes entes políticos em seu sentido etimológico. O estabelecimento do jus gentium cria três direitos relacionados à paz, cujos sujeitos são os próprios Estados: (i) o direito de estar em paz; (ii) o direito de ser assegurado por outros Estados; o direito de fazer a aliança com outros Estados, ou seja, o direito de participar da liga. A associação destes Estados em caráter universal proporciona a validade de tais direitos relativos a paz.

Por fim, no último estágio do direito público é o direito cosmopolita. Além do vinculo jurídico entre Estados, o cosmopolitismo possibilita uma abertura comercial entre eles. Assim, cada Estado tem o direito de se relacionar economicamente com outros, estando regidos pela mesma leis. O direito de trânsito também é característico do direito cosmopolita, podendo cada cidadão visitar qualquer lugar do globo terrestre.

Tendo sido apresentado uma breve noção sobre o entendimento de Kant sobre o direito público e suas três fases - o direito do Estado, o direito das gentes e o direito cosmopolita - verificar-se-á a problemática dos fundamentos do contrato social racional sob o qual o Estado kantiano é edificada em duas direções basilares: a liberdade e o direito privado.

\section{A DICOTOMIA ENTRE NATURRECHT E NATÜRLICHE RECHT}

O ponto final deste trabalho é apresentar as duas dimensões do direito natural no pensamento kantiano. Como acima dito, o direito para Kant tem basicamente três dimensões ou níveis, sendo uma delas o direito público, aquele fruto de um ato de vontade por uma autoridade do Estado, que produz uma legislação coercitiva e heterônoma.

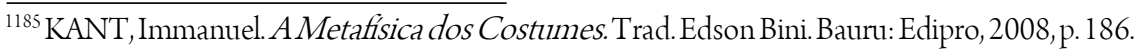


Além do direito público, Kant descreve uma noção direito natural que não pode ser meramente descrita como um direito natural como os pretéritos e dogmáticos pensadores modernos que tinham uma noção de direito natural preexistente a um direito do Estado e que pertencia a um mesmo plano ontológico, servindo geralmente de fundamento e legitimação para aquele.

O termo de natural no pensamento moderno em geral designa uma condição jurídica inerente a uma situação sem a existência de leis do ente estatal, ou seja, a existência de caracterização de juridicidade nas relações entre pessoas sem o Estado ou anteriormente a ele. Hobbes - o primeiro pensador com uma teoria propriamente moderna do direito e do Estado - estabelece um caminho de raciocínio baseado em fases, que posteriormente servirá de base para os demais contatualistas: um estado de natureza no qual o homem vive antes de existir o Estado, mas com uma condição jurídica - o direito natural - e uma diretriz racional - as leis racionais. No conflito entre o direito e as leis naturais, o homem destrói o estado de natureza com um ato, o pacto de submissão, e reconstrói o seu ambiente de relações interpessoais sob a forma de um constructo político, o Estado. Por isso, o estado de natureza é substituído por um Estado, um estado (no sentido aqui do particípio do verbo estar) civil. Estar-se civil o que outrora foi o estar-se na natureza.

Ainda que destruído após o pacto na teoria hobbesiana, o estado de natureza estabelece uma hipótese fundamental de legitimação do monopólio do direito emitido pelo Leviatã e no dever de obediência dos súditos, que são sujeitos do direito agora do Estado, não mais daquele natural inerente á sua condição de homo sapiens, a liberdade - no sentido de ausência de impedimentos físicos externos - de fazer e possuir o que quiser com o que é seu - tudo aquilo que puder conservar conquistado com suas próprias aptidões.

Sobre esse ponto da obra kantiana, leciona Soraya Nour:

No principio e na lei universal do direito podem ser identificados dois elementos básicos: a relação mútua dos arbítrios e a lei universal. A relação mútua dos arbítrios implica uma concepção de liberdade como limitação recíproca: a liberdade de cada um encontra seus limites na liberdade de outro. ${ }^{29}$

Em Kant o direito natural tem uma acepção diferente da hobbesiana já que o fundamento ultimo é bem diferente, a liberdade. Para o filósofo de Koenigsberg, como acima apresentado, a liberdade tem dois sentidos básicos que são bem diferentes de Hobbes e que são necessários para a justificação do direito natural na filosofia crítica.

Ao dissertar sobre a divisão geral dos direitos, Kant menciona o direito positivo, originário da vontade do legislador, característico como heterônomo e o direito natural, "o qual se apoia somente em princípios a priori". ${ }^{30}$ O que o autor quer dizer com isso? Que aquilo que pode ser chamado de direito natural é fruto dos princípios revelados pela razão pura prática - já que a metafísica não pode ser conhecida pela razão especulativa - sob a

${ }^{29}$ NOUR, Soraya. À Paz Perpétua de Kant: Filosofia do Direito Internacional e das Relações Internacionais. São Paulo: Martins Fontes, 2004, p. 25.

${ }^{30}$ KANT, Immanuel. A Metafisica dos Costumes. Trad. Edson Bini. Bauru: Edipro, 2008, p. 83 
forma de imperativos categóricos, fórmulas que exigem determinado comportamento de cumprimento do dever apenas pelo dever e não por outra finalidade.

Kant também observa sobre as justificativas morais que podem estabelecer deveres a alguém que podem resultar em direito inato e adquirido. O primeiro é aquele que todos os homens tem devido a sua condição natural, independentemente de um ato que os confira tais direitos; os segundos necessitam de um ato precedente para se configurarem como tal.

Kant distingue entre "direito inato" e "direito adquirido", lidando com o primeiro somente na Introdução da "Doutrina do Direito" e com o último somente sob a rubrica de "direito privado": ambos tornam-se obrigatórios através dos mecanismos políticos descritos sob "direito público" (basicamente, por meio de direito penal e civil, respectivamente, embora Kant não dizê-lo) A distinção entre o direito inato e o adquirido é, basicamente, que entre todos os direitos que todos deveriam ter sem o consentimento anterior dos outros e os direitos que as pessoas podem adquirir apenas através do consentimento dos outros, por exemplo, o direito à liberdade de uma agressão de um corpo sem provocação, e o direito à satisfação de uma parte da propriedade adquirido de alguém. ${ }^{31}$

O único direito inato do homem não é outro senão a própria liberdade; novamente citando o autor, "é o único direito original pertencentes a todos os homens em virtude da humanidade destes" ${ }^{\prime 2}$, e deve ser exercida em coexistência coma liberdade de todos os outros homens, sendo que todos eles devem agir conforme o imperativo categórico para serem livres conforme a lei moral e permitirem a liberdade conforme a lei doEstado.

O direito adquirido é detalhado sob a forma do direito privado por Kant na Doutrina do Direito. É interessante pensar que Kant explica esses direitos adquiridos como direitos ainda não concretizados, no sentindo uma pretensão subjetiva anterior ao direito público e dele dependente, se revestir em uma forma efetivamente jurídica.

Os conceitos de direito inato e adquirido direcionam às duas dimensões do direito que correspondem à uma ideia mais bruta de direito natural no pensamento kantiano; as duas dimensões que exatamente não são o direito público, mas que também não são a ele antagônicas: o natürliche Recht e o Naturrecht.

\footnotetext{
${ }^{31}$ GUYER, Paul. Kant. London: Routledge, 2006, p.226. Do original em inglês: "Kant distinguishes between "innate right" and "acquired right," dealing with the first only in the Introduction to the "Doctrine of Right"

and with only the latter under the rubric of "Private Right"; both of these in turn are to be enforced through the political mechanisms described under "Public Right" (basically, by means of criminal and civil law respectively, although Kant does not spell this out). The distinction between innate and acquired right is basically that between rights that everyone ought to have without the antecedent consent of others and rights that people can acquire only through the consent of others, for example the right to freedom from unprovoked assault on one's

body, on the one hand, and the right to enjoyment of a piece of property acquired from someone".

${ }^{32}$ KANT, Immanuel. A Metafísica dos Costumes. Trad. Edson Bini. Bauru: Edipro, 2008, p. 83
} 
Estas duas noções na filosofia kantiana para designar o direito natural são bem diferentes e expressam duas formas de fundamentação e legitimação do direito público: um estado de natureza de juridicidade provisória e uma diretriz material que estabelece limites e uma principal finalidade.

O natürliche Recht, que em uma perspectiva comparativa a Hobbes e Rousseau, seria o estado de natureza, mas que não se opõe ao Estado político. É um estado de sociabilidade, mas sem ainda a segurança recíproca necessária para a efetividade dos direitos; para tal é necessário autoridades para a criação de leis jurídicas (que são heterônomas, diferentes das racionais) e para sua aplicação, como osjuízes.

A reciprocidade é uma característica da ação do homem neste estado de natureza. O sujeito neste este estágio, conforme a posição de Goyard-Fabre ${ }^{33}$, não é um sujeito monádico, não é fechado em si mesmo para se obter tais direitos privados, já que não são inatos. Este argumento do homem kantiano no estado de natureza contraria a mais comum visão de atomismo social em Kant, uma vez que é necessária uma comunicabilidade entre os sujeitos e entre os sujeitos como parte com o todo.

Para Soraya Nour,

Toda concepção jurídica kantiana pressupõe, desde seu inicio, a intersubjetividade. A doutrina do direito não parte da noção de individuo, ou seja, da usual distinção entre o ser humano fora da sociedade, em um estado de natureza, e o ser humano em sociedade [...] ao contrário, parte da noção de individuo como membro de uma comunidade - seja uma comunidade sem Estado (direito privado), ou com Estado (direitopúblico). ${ }^{34}$

Kant disserta precisamente sobre o estado de natureza como um estágio de sociabilidade humana préEstado no $₫ 41$ da Doutrina do Direito. ${ }^{35}$ Inicialmente o autor, após dissertar largamente sobre o direito privado, define que que o estado de natureza é uma condição não jurídica, por não existir justiça pública - que por sua vez se subdivide em justiça protetiva, justiça comutativa e justiça distributiva. Neste mesma passagem Kant diferencia condição social e condição civil (na qual existe justiça distributiva). No estado de natureza "pode haver sociedades compatíveis com direitos (por exemplo, as sociedades conjugal, paternal, domesticas em geral, como muitas outras); porém, nenhuma lei 'deves ingressar nesta condição' vige a priori para essas sociedades" ${ }^{36}$

Essa condição ainda não jurídica, como explica Goyard-Fabre ${ }^{37}$, é pertencente à "humanidade da pessoa humana"; em razão de sua dignidade tem independência em relação ao próximo, mas não um isolamento, uma vez que a condição pré-jurídica que constitui o direito privado é resultante da comunicabilidade dos homens. A razão prática neste estado de natureza, cujo sentido é dado pelo direito privado, possui uma expectativa de ser direito.

\footnotetext{
${ }^{33}$ GOYARD-FABRE, Simone. Filosofia Crítica e RazãoJurídica. São Paulo: Martins Fontes, 2006, p. 141.

${ }^{34}$ NOUR, Soraya. O Legado de Kant à Filosofia do Direito. Prisma Jurídico, São Paulo, v.3, pp 91-103, set/2004.

${ }^{35}$ KANT, Immanuel. A Metafisica dos Costumes. Trad. Edson Bini. Bauru: Edipro, 2008, p. 150.

${ }^{36} \mathrm{Idem}$.

${ }^{37}$ GOYARD-FABRE, Simone. Filosofia Crítica e RazãoJurídica. São Paulo: Martins Fontes, 2006, p. 151.
} vol.09, nº. 02, Rio de Janeiro, 2016.pp. 1175-1193 
O direito privado é um estágio não jurídico produto das relações dos homens mas que não é originário deles, razão pela qual o autor o define como adquirido. ${ }^{38}$ Apesar da indefinição das diversas formas que o direito privado pode vir a ser tornar, o contrato é o ato racional por excelência que possibilita esta expectativa de juridicidade do direito privado.

O Naturrecht é a outra dimensão do direito natural, uma fundamentação transcendental do direito público. A noção de direito natural como Naturrecht é complexa em demasia. Essa concepção de direito natural é o direito intato de liberdade, que Kant inicialmente menciona na Introdução da Doutrina do Direito. Assim como o direito público, o direito privado enquanto natürliche Recht também encontra no Naturrecht seu fundamento, uma vez que pertence à uma categoria humana derivada de um comportamento baseado nalei racional.

Kant realiza uma ressignificação do direito natural, que não se refere mais natureza enquanto physis ${ }^{39}$ mas sim como instância transcendental de um ideal racionalista. ${ }^{40}$ Billier e Maryioli observam esta nova visão sobre trazida pela filosofia critica kantiana em dois aspectos básicos: "1. Pensando a humanidade do homem pela construção transcendental, fora da designação a ele de uma natureza humana qualquer; 2 . Fazendo do direito natural o horizonte, não mais a origem do direito positivo, o que sugere um papel ideal regulador e uma função crítica." $^{* 1}$

Otfried Höffe observa a natureza em uma caraterística moral, como desenvolvida por Kant: "o direito natural não faz parte da esfera teórica; ele faz parte, muito antes, dos princípios de liberdade. A 'natureza', no direito natural, nada tem a ver com a natureza (teórica) como abrangente do conceito de todoente". ${ }^{42}$

Da mesma forma, Palombella:

O conceito mesmo de 'natural' torna-se, em Kant, idêntico a racional; as leis naturais tornamse imperativos a priori da razão. $\mathrm{O}$ conceito de estado de natureza se traduz em ideia da razão. O direito, por sua vez, não é estudado por aquilo que historicamente vige, mas por

\footnotetext{
38 "Um direito pessoal jamais pode ser adquirido originalmente e com base na própria iniciativa (pois neste caso não se conformaria ao principio da coerência da minha escolha com a liberdade de todos e seria, consequentemente, errado) [...] A aquisição através do feito de outro indivíduo ao qual eu o determino de acordo com leis do direito é, consequentemente, sempre derivada dele" (KANT, Immanuel. A Metafisica dos Costumes. Trad. Edson Bini. Bauru: Edipro, 2008, p. 116).

39 "O que é natureza no naturalismo antigo? Duas coisas ao mesmo tempo, sem dúvida, que não se devem confundir: uma representação racional particular da natureza (uma 'física'), que não poderia evidentemente ser confundida com a própria natureza (em si), e que varia consideravelmente conforme se liga à física de Demócrates ou de Aristóteles, arrastando em seu sulco um ou outro tipo de jusnaturalismo antigo; e a ideia geral, partilhada além das diferenças entre físicos particulares, der que se pode colocar um outro ponto de vista sobre o direito positivo, que seria aquele de um conhecimento perfeito do que é perfeitamente justo: [...] aquele da natureza" (BILLIER, Jean-Cassien; MARYIOLI, Aglaé. História da Filosofia do Direito. Trad. Maurício de Andrade. Barueri: Manole, 2005, p.43)

40 “Uma variante fundamental do jusnaturalismo é representada pela filosofia de Kant (1724-1804), que não atribui à razão teórica (cognitiva) a tarefa de descrever postulados éticos ou jurídicos segundo os mesmos parâmetros dos fatos naturais, mas, ao contrário, confia à razão prática a definição de postulados gerais e abstratos, tanto quanto indefectíveis, de uma ordem ética universal baseada na liberdade". (PALOMBELLA, Gianluigi. Filosofia do Direito Trad. Ivone Benedetti. São Paulo: Martins Fontes, 2005, p. 7)

${ }^{41}$ BILLIER, Jean-Cassien; MARYIOLI, Aglaé. História da Filosofia do Direito. Trad. Maurício de Andrade. Barueri: Manole, 2005, p. 163.

${ }^{42}$ HÖFFE, Otfried. Justiça Política. Trad. Ernildo Stein. São Paulo: Martins Fontes, 2006, p. 88.
} vol.09, nº. 02, Rio de Janeiro, 2016.pp. 1175-1193 
aquilo que uma deducção racional define como pertencente ao justum e injustum e que está (ou deveria estar) no fundamento de toda legislação positiva. ${ }^{43}$

O Naturrecht determina uma forma devida á qual o direito público deve se adequar. Estabelece somente princípios a priori, revelados racionalmente pelo comportamento de acordo com o imperativo categórico, que determina a ação como se tal fosse uma lei universal. Kant "faz do direito natural enquanto Naturrecht uma ideia de razão', ou seja, a exigência universal e pura eu, inseridas nos próprios limites da razão prática, fundamenta toda ordem de direito em sua legitimidade jurídica" ${ }^{44}$.

Veja-se de novo que o sentido de liberdade é um dever que deve ser seguido por todos os homens agindo como manda a razão, de tal forma que suas ações se convertam em uma lei universal, ou seja, cada um deve agir como se esperassem de cada qual uma ação igual. Desta forma, a má-fé nos contratos, por exemplo, contraria o imperativo categórico e consequentemente a própria liberdade humana porque ninguém deve agir a fazer um negócio com a intenção de não cumpri-lo, já que não se pode esperar das outras partes o não cumprimento. Assim, todas as pessoas devem agir com boa-fé porque se pressupõe que todos os homens agem de boa-fé; esta deve ser a regra. Logo, a ação de boa-fé é uma ação moralmente boa e racionalmente coerente. Assim, quando o homem age de boa-fé, ele está sendo livre porque cumpre a lei moral.

Todos os homens em razão de serem homens são livres, mas livres por serem racionais. A razão é inerente ao homem, logo a liberdade é um direito inato de cada homem devido á sua autonomia, capacidade de reconhecer e seguir a máxima moral.

A liberdade como direito inato é fundamento último para o Estado e o princípio universal do direito: "qualquer ação é justa e for capaz de coexistir com a liberdade de todos de acordo com uma lei universal, ou se na sua máxima liberdade de escolha de cada uma puder coexistir com a liberdade de todos de acordo com uma lei universal". ${ }^{45} \mathrm{~A}$ liberdade não está relacionada somente à ação moralmente boa, mas também com a coexistência do exercício das liberdades sob égide de uma lei universal. Novamente, o Estado, para Kant, é a "união de uma multidão de seres humanos submetidas a leis de direito". ${ }^{46}$

Essas leis de direito tem como único fim si mesmo, "no sentido de que lhe compete exclusivamente assegurar a ordem jurídica, garantir a cada um a liberdade exterior que the permita determinar os seus próprios critérios morais e procurar a felicidade pessoal" ${ }^{47} \mathrm{O}$ direito tem somente a finalidade de não interferir na vida moral dos cidadãos do Estado; deve apenas assegurar mediante leis que todos possam exercer sua autonomia.

\footnotetext{
${ }^{43}$ PALOMBELLA, Gianluigi. Filosofia do Direito Trad. Ivone Benedetti. São Paulo: Martins Fontes, 2005, p. 70.

${ }^{44}$ GOYARD-FABRE, Simone. Filosofia Crítica e Razão Jurídica. São Paulo: Martins Fontes, 2006, pp.153-154

${ }^{45}$ KANT, Immanuel. A Metafísica dos Costumes. Trad. Edson Bini. Bauru: Edipro, 2008, p. 76.

${ }^{46}$ KANT, Immanuel. A Metafisica dos Costumes. Trad. Edson Bini. Bauru: Edipro, 2008, p. 155.

${ }^{47}$ NOVAIS, Jorge Reis. Contributo para uma Teoria do Estado de Direito. Coimbra: Almedina, 2006, p. 66.
} _vol.09, nº. 02, Rio de Janeiro, 2016. pp. 1175-1193 
Dentro desta ideia de direito inato de cada ser humano de ser livre agindo pela moral, está o que Kant desenvolve como o direito natural inato, o Naturrecht. É da natureza do homem moralmente, no sentido de ser autônomo para conhecer as regras de moralidade e escolher se comportar conformeelas.

\section{CONSIDERAÇÕES FINAIS}

A filosofia crítica de Immanuel Kant modificou a forma de se pensar o direito moderno e possibilitou uma ressignificação na ideia de direito natural, até então mergulhado em um "sono dogmático". Evidentemente a descrição kantiana sobre o direito é o resultado de suas reflexões iniciais sobre epistemologia desenvolvidas na Crítica da Razão Pura.

O sujeito racional é colocado no centro da filosofia crítica; Kant mais que todos os seus contemporâneos e antepassados expressa o paradigma do sujeito. A realidade é moldada pela atividade racional do indivíduo e é concebida como o resultado da perfeita leitura do mundo realizada pelo serhumano.

Não sendo possível ser alcançada pelo conhecimento especulativo, a liberdade é realizada pela razão prática devido a condutas do homem reveladas pela sua própria capacidade de pensar racionalmente. A razão, chave para a liberdade, guia a vontade humana por meio de leis racionais, comandos que são originados dela própria; neste sentido, o homem é capaz de se comportar de acordo com leis reveladas de forma apriorística, o que gera a condição de autonomia. Estas leis racionais são leis morais.

A moralidade do agir é guiada por um tipo de comando racional que estabelece um dever sem uma finalidade para sua destinação, o denominado imperativo categórico. Este comando racional revela uma máxima que determina que o homem deva agir como se tal conduta seja transformada em uma lei racional universal; desta forma, cada homem deve agir como se sua ação fosse esperada e realizada também por todas as outras pessoas. A vontade de agir conforme este imperativo de moralidade deve ser motivada apenas pelo dever de agir pelo dever, sem de deixar desviar por impulsos emocionais. Quando o homem age moralmente, ele exerce sua liberdade.

A liberdade é o único direito inato de cada homem. É uma perspectiva transcendental da razão prática pura. Não existe como conceito empírico, mas apenas como uma ideia a priori que fundamenta toda a doutrina do direito de Kant. Este direito inato, transcendental, é de direito natural enquanto Naturrecht, uma ideia racional de liberdade.

O Naturrecht por sua vez ser de fundamento para outra designação de direito natural na filosofia crítica kantiana, o natürliche Recht, que corresponde a um direito privado em um estado de natureza racional, mas sem a existência ainda do direito público. Nesta situação, o direito privado é apenas um direito provisório, sendo adquirido como por meio das ações humanas guiadas pela vontade livre - de acordo com a lei moral possibilitada pelo direito inato. Para se confirmar como peremptória, o natürliche Recht, necessita da saída desta 
condição de racionalidade para uma realidade política, por meio de um contrato social, após o qual é formado o öffentliche Recht, o direito público.

O direito público, formado pela união das vontades em uma grande vontade geral, tem por sua vez três níveis: o primeiro é o direito do Estado, formado pela associação dos homens, dotado de poder soberano que se manifesta em três poderes necessários e subordinados a uma Constituição - que neste sentido kantiano como uma forma jurídica correspondente à ideia transcendente do Naturrecht - que deve ser republicana.

No nível do direito público acima do Estado estão o direito das gentes, que regulamenta a conduta dos Estados livres, cuja grande finalidade é a condição de paz, e o direito cosmopolita, em um ideal racional federalista epacifista.

A filosofia jurídica crítica kantiana provocou uma nova estruturação do direito natural de uma índole racionalista diferente da desenvolvida por Grotius ou Hobbes no Século XVII. O direito natural deixa de ser uma condição empírica ou metafísica e passa a ser entendido como uma condição pura da razão prática e serve como fundamento regulador do direito público, não mais meramente suaorigem.

\title{
THE THREE DIMENSIONS OF LAW IN PHILOSOPHY CRITICAL OF KANT
}

\begin{abstract}
This article presents the three dimensions of the Law within the critical philosophy of Immanuel Kant and its specifications. First will be seen as freedom is expressed by a practical and rational action, as opposed to knowledge of traditional metaphysics until then. Human autonomy allows freedom is possible, both in the moral world, as in the State. Later this work will demonstrate the division of Law in the writings of Kant, in public Law and natural Law. While the former is clearly identified with the rules issued by authorities in three levels (the law of the State, the law of nations and cosmopolitan law), the second has two different meanings: the natural legislation while private law, without existence of the State and the innate natural law (Naturrecht), the realization of freedom, and the ultimate foundation of both the private and the public, in whatever their level
\end{abstract}

Keywords: Immanuel Kant; Naturrecht; Freedom.

\section{REFERENCIAS BIBLIOGRÁFICAS}

BILLIER, Jean-Cassien; MARYIOLI, Aglaé. História da Filosofia do Direito. Trad. Maurício de Andrade. Barueri: Manole, 2005, p. 163.

GOYARD-FABRE, Simone. Filosofia Crítica e Razão Jurídica. São Paulo: Martins Fontes, 2006

GUYER, Paul. Kant. London: Routledge,2006 
HÖFFE, Otfried. Justiça Política. Trad. Ernildo Stein. São Paulo: Martins Fontes, 2006, p.88.

KANT, Immanuel. A Metafísica dos Costumes. Trad. Edson Bini. Bauru: Edipro, 2008

Crítica da Razão Pura 2 ed.Trad. Valério Rohden. São Paulo: Abril Cultural, 1983

Fundamentação da Metafísica dos Costumes. São Paulo: Abril Cultural, 1983

NOUR, Soraya. À Paz Perpétua de Kant: Filosofia do Direito Internacional e das Relações Internacionais. São Paulo: Martins Fontes, 2004

O Legado de Kant à Filosofia do Direito. Prisma Jurídico, São Paulo, v.3, pp91-103, set/2004.

NOVAIS, Jorge Reis. Contributo para uma Teoria do Estado de Direito. Coimbra: Almedina, 2006

PALOMBELLA, Gianluigi. Filosofia do Direito Trad. Ivone Benedetti. São Paulo: Martins Fontes, 2005, p. 70.

SANDEL. Michael. Justiça: O que é fazer a coisa certa Trad. Heloisa Matias. Rio de Janeiro: Civilização Brasileira, 2012

Trabalhoenviadoem09denovembrode2015.

Aceitoem 12 dejaneiro de2016. 